\title{
A NOTE ON THE BUD COUNT METHOD OF FORECASTING CONE CROPS OF DOUGLAS FIR ${ }^{1}$
}

\author{
J. M. FINNIS 2
}

\section{J. M. (Mike) FINNIS}

Age - 32 years, Born London (Eng.) After the war read Forestry at Oxford University and in 1948 obtained the degree of Bacbelor of Arts. In the same year came to Canada and joined the Research Division (then the Economics Division) of the Britisb Columbia Forest Service. At present working on problems connected with rodent control and direct seeding.

"Mike" accepted "the King's sbilling" in 1940 and served the ensuing five years with the British Army (Royal Artillery) attached to the 1st Indian Field Regiment, Indian Artillery. He saw active service in Burma as a lieutenant.

\section{$A B S T R A C T$}

In 1941 G. S. Allen described a method of forecasting cone crops of certain coniferous species. In.1949 a small scale experiment was conducted, using the method on second growth Dotrglas fir. After a little practice it was found that the buds due to mature in the following year could be correctly identified in November. The ratio of the female/vegetative buds, known as "cone intensity" is a measure of the cone crop to be expected in the following year. Before cone maturity in the following year, there are many adverse factors which must be considered and which modify the forecast. The practical value of the forecast is reduced by the time taken to make the bud count and the many problems involved in obtaining an adequate and accurate sample.

In all forestry operations a knowledge of the cone crop in the year ahead would be valuable. To the forest manager such a forecast might be the deciding factor in choosing which area should be logged, other things being equal. In 1941, Allen described a basis for forecasting seed crops of some coniferous trees (1). This included Douglas fir.

After the end of August the reproductive and vegetative buds of the following year can be distinguished. A high production of female buds gives promise of a cone crop. The ratio of the female/vegetative buds in a sample is independent of crown size and Allen calls this ratio "cone intensity". "Cone intensity" is used as a measure of the cone crop to be expected. This study was made to test the accuracy and practicability of the method.

\section{METHOD}

Bud counts were made on 17 trees, in three localities, on Lower Vancouver Island, in November, 1949. The trees were second-growth Douglas fir (Pseudotsuga taxifolia. Britt.) between 20 and 40 years old.

1. B.C. Forest Service Technical Publication $T 39$

2. Assist. Forester, Research Division, B.C. Forest Service, Victoria, British Columbia. 
CONE CROPS-FINNIS

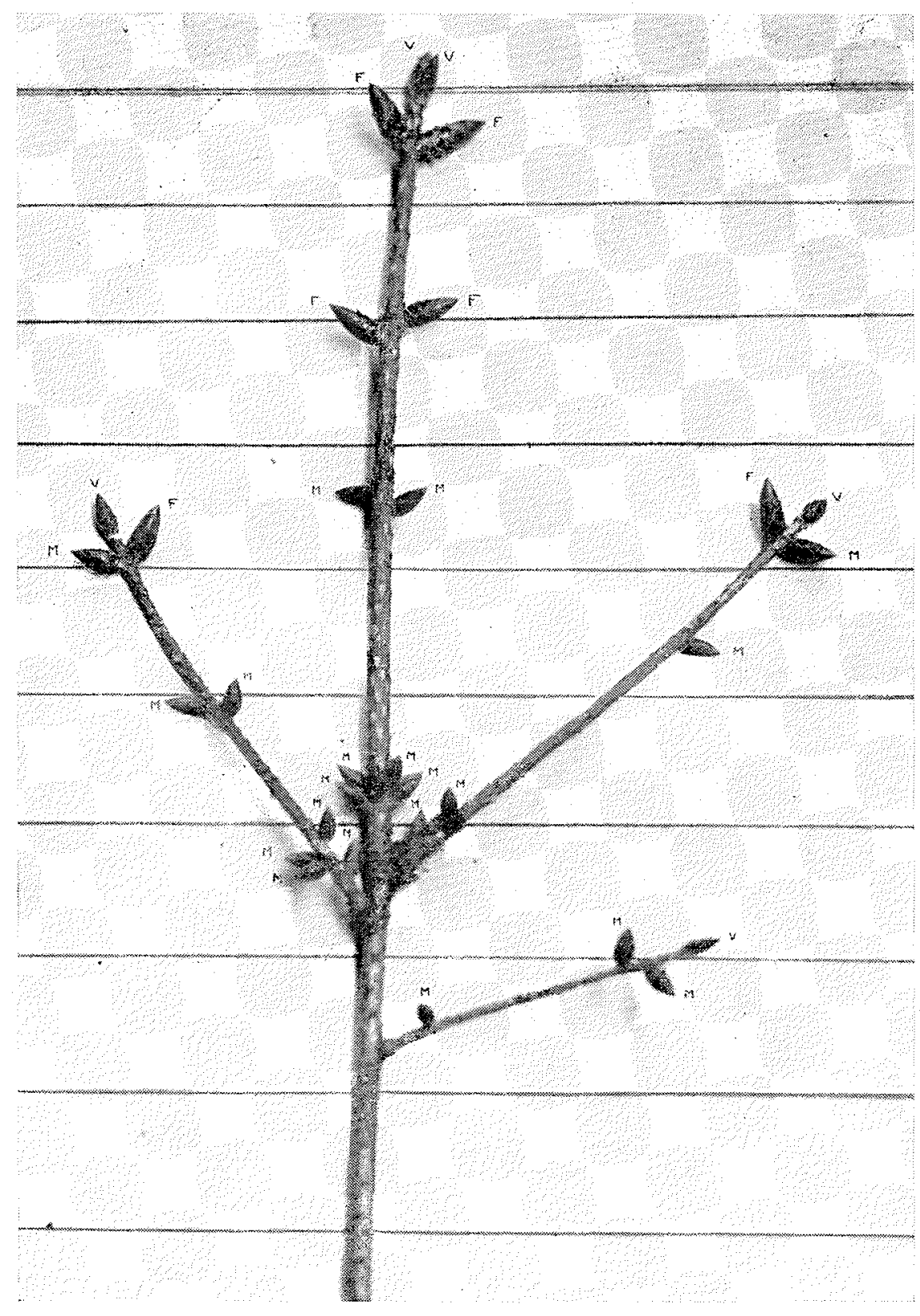


124 FORESTRY CHRONICLE

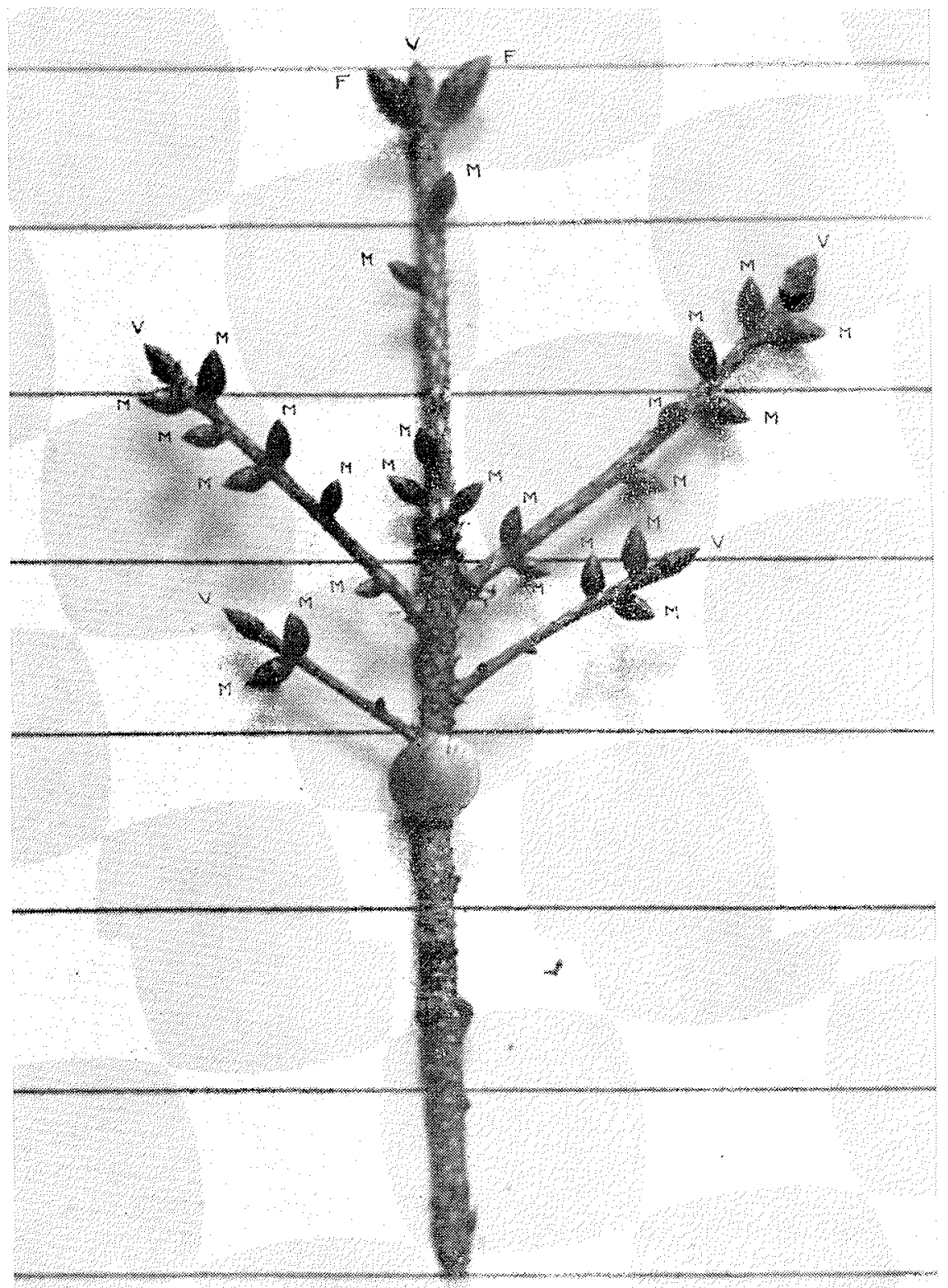


On each tree, five branches on the east side and five branches on the west side were tagged. The branches were about $2 / 3$ of the way up the tree or as high as it was reasonably possible to climb. At the end of each branch the buds on the 1949 growth were identified and tallied. Counts were also made on the 1949 growth arising from the 1948 laterals immediately back from the leader. Specimens of typical buds are shown in Plates 1 and 2. There appear to be no hard and fast rules for identification, except that the terminal bud on leaders and lateral branchlets is always vegetative. In general, the vegetative buds are darker in color, and the scales more conspicuous than on reproductive buds. The female buds are larger and fatter than either the male or vegetative buds, and they tend to be in pairs at the end of the branches and branchlets, flanking the terminal vegetative bud. The male buds are usually thin and pointed, and although somewhat like the vegetative buds, tend to be smoother and lighter in color than the latter. The male buds are found (a) in clusters near the base of the current years growth (as in Plate 1) or (b) scattered individually along the length of the branch (as in Plate 2). If the buds are cut longitudinally they can be identified with the naked eye. When making a count the best method was to cut a few buds on each tree and identify them. This gave an idea of the pattern of the buds on the particular tree and the relative size of the different buds.

In August, 1950 a cone count was made of the tagged branches.

\section{RESULTS}

The results of the bud counts and cone counts on the 17 trees are shown in Table 1.

\section{CONCLUSIONS}

Two facts are apparent from this table:

1. The trees selected for the study had few female buds and, consequently, there was meagre data for testing the method.

2. The bud identification was good and has practical applications.

A "cone intensity" of 0.25 or better indicates a very good cone crop; a ratio of from 0.15 to 0.20 , indicates a good cone crop. But the production of female buds was so small that the accuracy of these estimates could not be tested.

In addition to these factors influencing the accuracy of the bud-count method, there are certain practical limitations. If the method is to be an aid

\section{CAPTYONS}

PLATE 1. Showing bud identification.

$$
\text { "Cone Intensity", } \quad \frac{\text { female }}{\text { vegetative }} \quad \text { buds }=1.2
$$

PLATE 2. Showing bud identification.

$$
\text { "Cone Intensity", } \frac{\text { female }}{\text { vegetative }} \text { buds }=0.4
$$




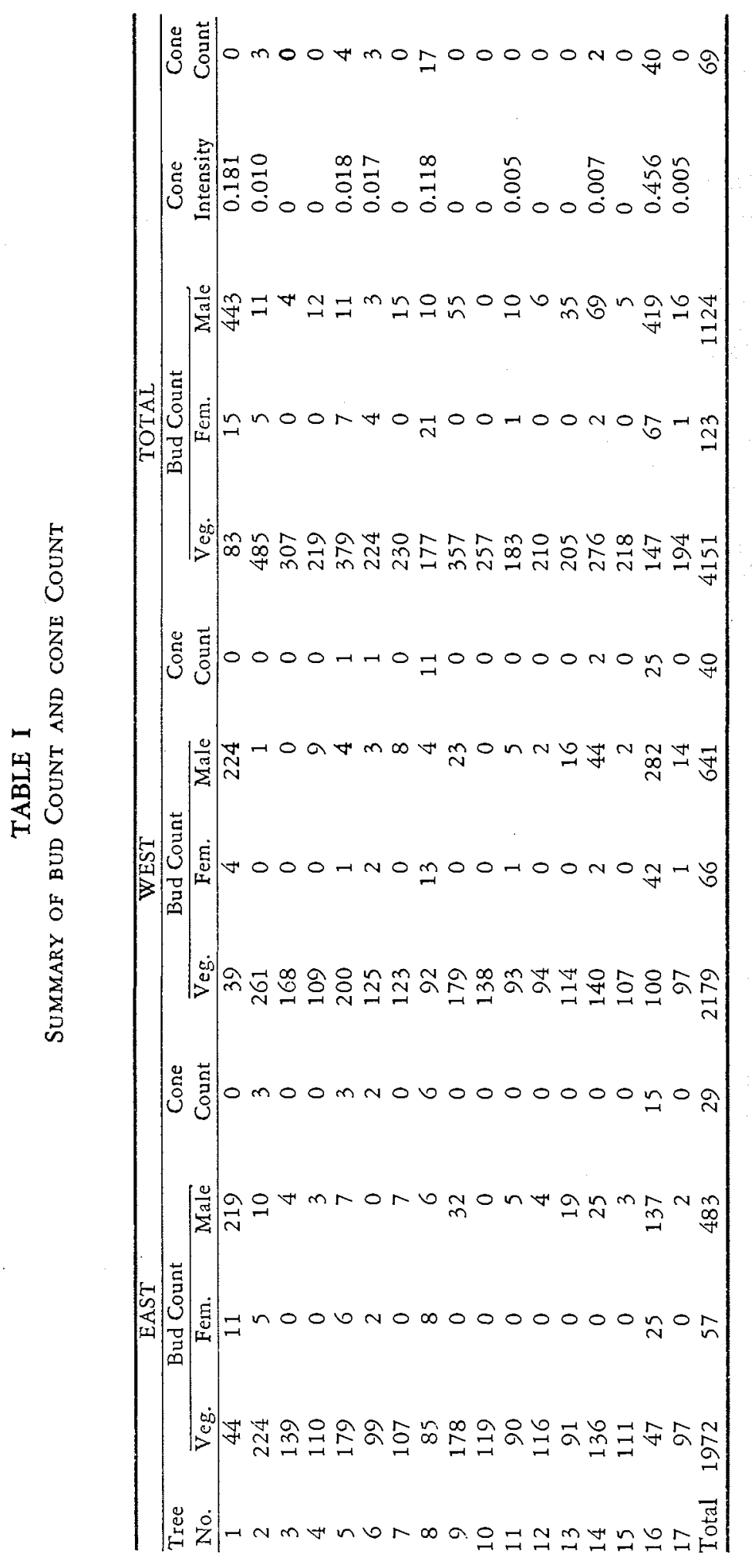


to the forest manager in securing natural regeneration, how is he going to sample mature timber? The trees used in this study were only 35-55 feet high, were open grown, and had branches down to the ground. In this study the field work took two men four days. This time could be lessened by reducing the size of the sample per tree. However, there remains the problem of how many trees should be sampled to give an accurate picture of the area in question. When the cone intensity indicates a cone crop, this forecast must be modified for adverse factors, the chief of which are unfavorable weather at critical stages in development, insect damage, and abortion.

Summing up, while quite an accurate estimate can be made, which must be modified by the adverse factors, the practical difficulties severely limit the usefullness of the method.

\section{REFERENCES}

1. ALLEN, G. S. A basis for forecanting seed crops of some coniferous trees. Jour. For. 39: $1014-6$. 